\title{
A Systematic Review of Transfusion-Transmissible Infections Among Blood Donors and Associated Safety Challenges in Pakistan
}

This article was published in the following Dove Press journal:

Journal of Blood Medicine

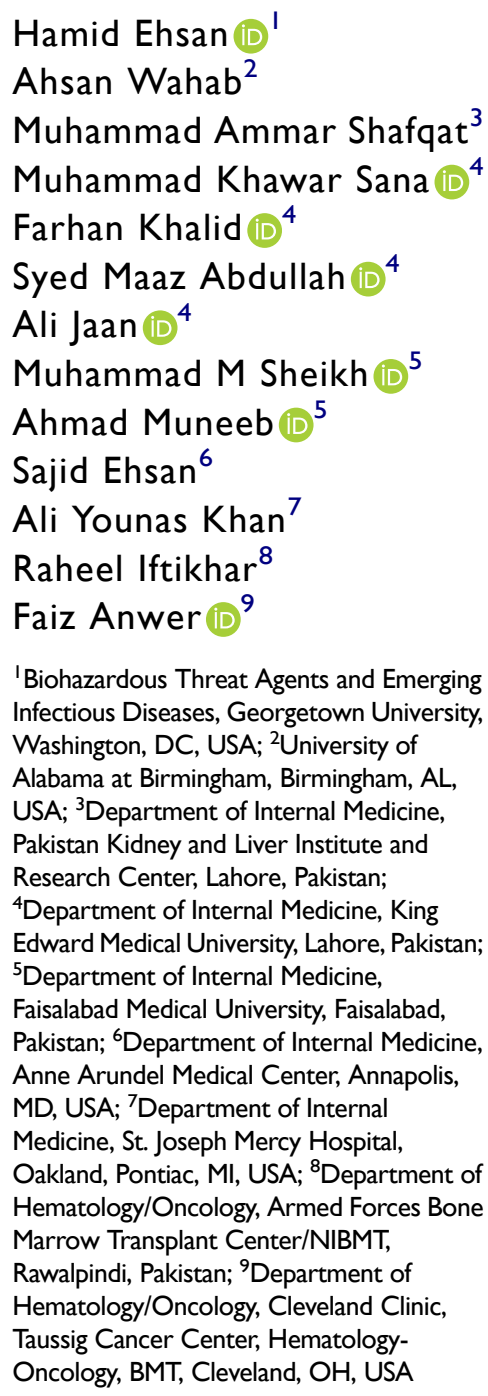

Correspondence: Hamid Ehsan MD, FACP MUMH, Department of

Medicine, 20I E. University Parkway,

Baltimore 21218, USA

$\mathrm{Tel}+19172875423$

Fax +14105542184

Email heI50@georgeotown.edu

\begin{abstract}
The blood transfusion (BT) system in Pakistan is fragmented, demand-driven and depends on weakly regulated transfusion practices. There is a considerable possibility that transfusion-transmissible infections (TTIs) are contributing to the current epidemic of hepatitis B virus (HBV) and hepatitis C virus (HCV) (affecting 7.4\% of the general population) in the country. To study this issue, we conducted a systematic review to identify articles related to TTIs and transfusion safety in Pakistan from January 1, 2010 to January 31, 2020. A review of 33 articles met the final criteria for qualitative synthesis. Analysis of these studies showed a cumulative frequency of HBV $2.04 \%$, HCV $2.44 \%$, HIV $0.038 \%$, syphilis $1.1 \%$ and malaria $0.11 \%$. The frequency of coinfections among blood donors varied from $0.0099 \%$ to $0.35 \%$. The highest number of coinfections were HCV and syphilis, followed by HCV and HBV infections. Syphilis and malaria were tested in only $38 \%$ and $46 \%$ of all the blood donations in one study. The rate of voluntary non-remunerated donations (VNRDs) was less than $13 \%$, and male donors were $95 \%$ to $100 \%$ in these studies. There was a significant difference in the frequency of HBV and HCV in VNRDs $(0.48 \%)$ as compared to replacement donors (RDs) (4.15\%). In short, this review shows a high frequency of TTIs, especially HBV, HCV and syphilis in the blood donor population in Pakistan. There is a high dependency on RDs, minimal use of healthy voluntary blood donation practices, inadequate screening of high-risk donors, repeated collections of the blood from RDs, poor quality of screening methods and limited knowledge of donor health. Without standardized safe transfusion practices, there will be an ongoing increase in transmission of TTIs, especially HBV, HCV, syphilis, and HIV leading to a significant adverse public health impact.
\end{abstract}

Keywords: transfusion-transmitted infections, hepatitis B, hepatitis C, HIV, syphilis, malaria

\section{Introduction}

Blood transfusion (BT) is an essential lifesaving treatment and is an integral part of the World Health Organization (WHO) list of essential medicines. ${ }^{1}$ WHO recommends achieving self-sufficiency to meet the transfusion needs of a population with a safe supply of blood components based on voluntary, non-remunerated blood donations (VNRDs) along with a security of supply chain for providing safe endproduct to patients. ${ }^{1}$ An estimated 3.5 million blood donations are collected every year in Pakistan. ${ }^{2}$ Blood transfusions are used mainly for chronically transfusion-dependent thalassemia patients, anemia due to poor health conditions, acute trauma, surgical procedures, hemorrhage and pregnancy-related complications. ${ }^{5}$ An estimated one-fourth of the national annual blood collections are used for 
transfusion-dependent thalassemia patients. ${ }^{6}$ Pakistan has one of the highest hepatitis B virus (HBV) and hepatitis $\mathrm{C}$ virus (HCV) prevalence (5 and 10 million, respectively) in the world and unsafe BT practices are further fueling this epidemic. ${ }^{3}$ Blood-borne transmissions remain a crucial vector for transmission of $\mathrm{HBV}$ and $\mathrm{HCV}$ infections, affecting about $7.4 \%$ of the general population. ${ }^{4}$ The maternal mortality rate in Pakistan is one of the highest in the world (276/100,000 live births) and the major causes of maternal deaths are due to complications of anemia and bleeding. $^{7}$

Major challenges for BT safety in Pakistan include the high prevalence of $\mathrm{HBV}$ and $\mathrm{HCV}$ infections in the general population, lower rates of voluntary donations, lack of standardized screening measures of donors and limited reporting of TTIs. In addition, blood banks (BBs) in Pakistan transfuse most blood as whole blood though the concept and facilities for blood component therapy (red blood cells, platelets, and plasma) is evolving in urban and tertiary care centers. Rural areas, however, face significant difficulty in accessing safe BT products. This leads to unsafe practices in the supply chain, lack of knowledge and adherence to the WHO guidelines and the use of improperly screened blood.

WHO strategy for universal safe blood transfusion places an emphasis on the development of a wellcoordinated BT system with an exclusive collection of blood from VNRDs, quality-assured donor testing, evidence-based use of BT practices, development of universal quality and monitoring metrics. ${ }^{8}$ To raise the standard of BT safety according to the WHO guidelines, Pakistan has developed the "Safe Blood Transfusion Program (SBTP)" which was launched in 2010 with financial support from the German government and technical aid from the WHO. Its role is that of a central coordinating body at the federal level. The purpose of this program includes the development of a nationwide infrastructure of a new BT system. ${ }^{5}$ It led to the development of 10 modern Regional Blood Centers (RBCs) and modernization of 60 existing Hospital Blood Banks (HBBs) in Phase I. SBTP Phase II is currently underway with a 10 million euros grant through the German Development Bank (KfW). It includes the expansion of RBCs' network and upgrades to existing HBBs. ${ }^{5}$

In this review, we estimated the frequency of transfusion-transmissible infections (TTIs) in the donor population to estimate the burden of TTIs through blood transfusions and reviewed various safety challenges associated with the BT system in Pakistan.

\section{Materials and Methods}

\section{Search Strategy}

We carefully conducted a comprehensive search of PubMed and PakiMediNet from inception to January 31, 2020 with no language restriction. The search queries were transfusiontransmitted infections, transfusion-related infections, TTIs and blood transfusion infections in Pakistan. Two authors (AW/HE) screened titles and abstracts of all identified results independently. Another two authors (MAS/MKS) reviewed the full-text articles according to the predefined inclusion and exclusion criteria. Discrepancies were resolved through discussion. In addition, the reference lists of potentially eligible studies were hand-searched to avoid overlooking any eligible studies. Our research did not require IRB approval or written consent.

\section{Inclusion and Exclusion Criteria}

Inclusion criteria were: 1) studies with more than 50 participants and 2) studies that showed the frequency of common TTIs (HBV, HCV, HIV, malaria, syphilis) in donor populations.

Exclusion criteria: 1) case reports, abstracts without full-length articles, meta-analysis and systemic reviews, 2) studies with uncommon TTIs such as West Nile virus, dengue fever and human T-lymphocyte virus-1/2, 3) studies with the frequency of TTIs in chronically transfusiondependent patients of thalassemia major and hemophilia.

\section{Data Extractions}

Two authors independently extracted data (HE/AW) from the included studies including author, number of patients, type of donors, seropositive status of HBV, HCV, HIV, malaria, syphilis and coinfection.

\section{Eligible Studies}

A total of 981 studies were identified based on initial database search and 857 studies remained after removing duplicates. After reviewing titles and abstracts, 166 studies were retrieved for full-length article review according to predefined inclusion and exclusion criteria. We excluded 133 studies for reasons indicated in the PRISMA flow chart (Figure 1). Thirty-three studies were finally included in our systematic review.

\section{Definition for Positive Transfusion-Transmissible Infections}

A blood donor was labelled positive for any particular TTI if reported reactive by the study irrespective of the type of investigation used. 


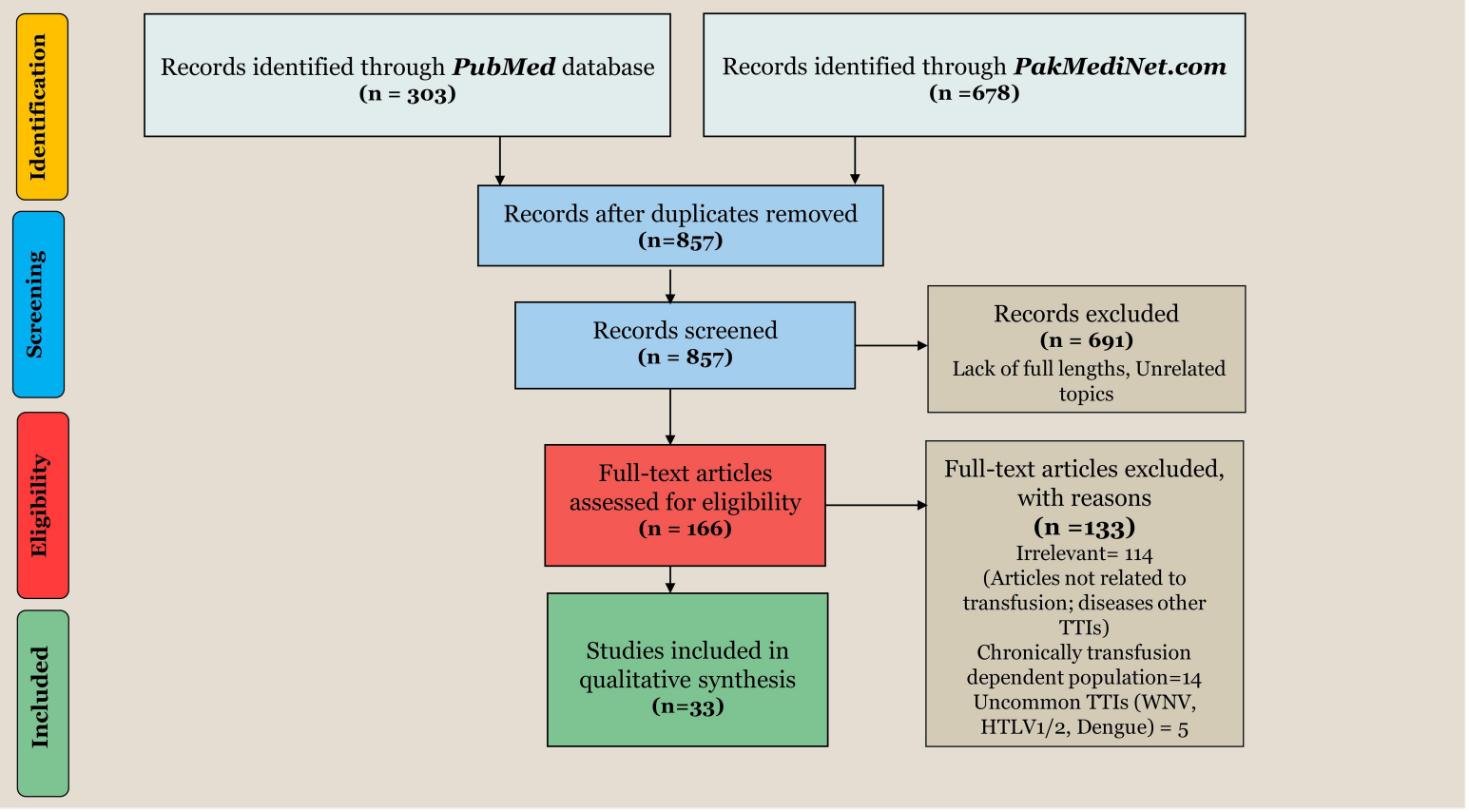

Figure I PRISMA flow diagram showing a summary of selection process.

Note: Copyright (C) 2009, Public Library of Science. Adapted with permission from Moher D, Liberati A, Tetzlaff J, Altman DG, PRISMA Group. Preferred reporting items for systematic reviews and meta-analyses: the PRISMA statement. PLoS Med. 2009;6(7):el000097.

\section{Frequency of Transfusion-Transmissible Infections}

The frequency (in percent) for any particular TTI in individual study was calculated as total number of donors with reactive TTI/total donor population screened multiplied by 100. We calculated the cumulative frequency of TTIs in the donor population, ie, the total number of donors reactive for a particular TTI in individual studies divided by the total donor population of all studies screened.

\section{Diagnostic Methods for TTls Used in Studies}

Diagnostic methods used for detection of TTIs in these studies were diverse with variable sensitivity and specificity. Methods used included immunochromatographic methods (ICT), enzyme-linked immunosorbent assay (ELISA), microparticle enzyme immunoassay (MEIA), chemiluminescence assay (CIA) and nucleic acid amplification test (NAT).

\section{Results}

The characteristics of 33 studies included in the systemic review are given in Table 1. These studies used BBs' data of large metropolitan cities in Pakistan such as Karachi, Hyderabad, Islamabad, Rawalpindi, Lahore, Faisalabad and Peshawar. Twenty-eight studies $(n=672,199)$ evaluated the frequency of either HBV, HCV or both among donors
(Table 2). Twenty-three studies $(n=1,339,689)$ focused on the frequency of HIV, syphilis or malaria (Table 3).

\section{Blood Transfusion Donors in Pakistan}

Replacement donors (RDs) are the major type of donors in Pakistan with VNRDs ranging between $0.10 \%-13 \% .^{11,13,19,20,22,23,28,29,33-35}$ The proportion of blood donations by VNRDs varied between $0 \%$ and $91 \%$ across 19 BBs in one study, $8.25 \%$ of all donations were due to VNRDs and seven BBs had no donations by VNRDs. ${ }^{19}$ Male donors comprised 95\% to $100 \%$ of all blood donations. Donors were more prevalent in younger age groups. ${ }^{12,13,22}$ Female donors ranged between $0 \%$ and $9.6 \%$ in individual studies $^{9,12,13,18,20,22}$ One study with data from both private and public BBs reported a higher proportion of female donors in private BBs versus public BBs, $29 \%$ vs $15 \%, \mathrm{p}<0.01 .^{16}$

\section{Transfusion-Transmissible Infections in Pakistan}

The frequency of TTIs in blood donors varied among studies depending on donor types, number and types of TTI tested and screening methods. In 11 studies, authors screened donors for three or more TTIs (HBV, HCV, 
Table I Characteristics of Studies $(n=33)$ Included in a Systematic Review

\begin{tabular}{|c|c|c|c|c|c|c|c|}
\hline $\begin{array}{l}\text { Author, } \\
\text { Year }\end{array}$ & Design & Duration & $\begin{array}{l}\text { Age in } \\
\text { Years } \\
\text { (Range) }\end{array}$ & $\begin{array}{l}\text { Male } \\
(\%)\end{array}$ & $\begin{array}{l}\text { No. of } \\
\text { Donors }\end{array}$ & Investigation & Diagnostic Methods \\
\hline $\begin{array}{l}\text { Shah et al, } \\
2010^{9}\end{array}$ & $\begin{array}{l}\text { Retrospective } \\
\text { cross- } \\
\text { sectional }\end{array}$ & $\begin{array}{l}\text { Jan } 2007- \\
\text { Dec } 2008\end{array}$ & $(18-52)$ & 100 & 32,042 & $\mathrm{HBsAg}$, anti-HCV Abs & ELISA \\
\hline \multirow{2}{*}{$\begin{array}{l}\text { Ansari } \\
\text { et al, } \\
2012^{10}\end{array}$} & \multirow{2}{*}{$\begin{array}{l}\text { Cross- } \\
\text { sectional }\end{array}$} & \multirow{2}{*}{$\begin{array}{l}\text { Jan } 2010- \\
\text { Dec } 2010\end{array}$} & \multirow[t]{2}{*}{ NA } & \multirow[t]{2}{*}{ NA } & \multirow[t]{2}{*}{5517} & $\mathrm{HBsAg}$ & ELISA, Bio kit, Spain \\
\hline & & & & & & $\begin{array}{l}\text { Anti-HCV Abs, anti-HIV } \\
\text { Abs }\end{array}$ & $\begin{array}{l}\text { ELISA kit, General Biological } \\
\text { Cooperation, Taiwan }\end{array}$ \\
\hline \multirow{5}{*}{$\begin{array}{l}\text { Waheed } \\
\text { et al, } \\
2012^{11}\end{array}$} & \multirow{5}{*}{$\begin{array}{l}\text { Retrospective } \\
\text { cross- } \\
\text { sectional }\end{array}$} & \multirow{5}{*}{$\begin{array}{l}\text { Jan } 2010- \\
\text { Dec 2011 }\end{array}$} & \multirow[t]{5}{*}{ NA } & \multirow[t]{5}{*}{ NA } & \multirow[t]{5}{*}{10,145} & Anti-HCV Abs & ELISA NANBASE C-96 3.0 \\
\hline & & & & & & $\mathrm{HBsAg}$ & ELISA \\
\hline & & & & & & Anti-HIV Abs & DIMS's ELISA \\
\hline & & & & & & Syphilis RPR & RPR IMMUTREP \\
\hline & & & & & & Malarial parasite & Biotech ICT \\
\hline $\begin{array}{l}\text { Attaullah } \\
\text { et al, } \\
2012^{12}\end{array}$ & Retrospective & $\begin{array}{l}\text { Jan } 2008- \\
\text { Jun } 2011\end{array}$ & NA & 99.96 & 127,828 & $\begin{array}{l}\text { HBsAg, anti-HCV Abs, } \\
\text { anti-HIV Abs, VDRL }\end{array}$ & ELISA BEST 2000, Biokit, Spain \\
\hline $\begin{array}{l}\text { Irfan et al, } \\
2013^{13}\end{array}$ & $\begin{array}{l}\text { Cross- } \\
\text { sectional }\end{array}$ & $\begin{array}{l}\text { Jan 2004- } \\
\text { Dec 20II }\end{array}$ & $\begin{array}{l}28.9 \\
(17-55)\end{array}$ & 99.85 & 108,598 & $\begin{array}{l}\text { HBsAg, anti-HCV Abs, } \\
\text { anti-HIV Abs }\end{array}$ & $\begin{array}{l}\text { MEIA, Axsym system, till } 201 \mathrm{I} \\
\text { then CIA, Architect i2000, Abbott } \\
\text { Diagnostic, USA }\end{array}$ \\
\hline $\begin{array}{l}\text { Tunio et al, } \\
2013^{14}\end{array}$ & $\begin{array}{l}\text { Retrospective } \\
\text { cross- } \\
\text { sectional }\end{array}$ & $\begin{array}{l}\text { Jan } 2012- \\
\text { Jun } 2012\end{array}$ & NA & NA & 2696 & Anti-HBs, $\mathrm{HBsAg}, \mathrm{HBeAg}$ & $\begin{array}{l}\text { MEIA, Architect, Abbott } \\
\text { Diagnostic, USA }\end{array}$ \\
\hline $\begin{array}{l}\text { Tufail et al, } \\
2013^{15}\end{array}$ & Descriptive & One year & $(20-40)$ & NA & 1833 & $\begin{array}{l}\text { HBsAg, anti-HCV Abs, } \\
\text { anti-HIV Abs }\end{array}$ & Chemiluminescence assay \\
\hline $\begin{array}{l}\text { Sulehri } \\
\text { et al, } \\
2013^{16}\end{array}$ & $\begin{array}{l}\text { Cross- } \\
\text { sectional }\end{array}$ & $2010-2011$ & NA & 78 & 600 & Anti-HCV Abs & $\begin{array}{l}\text { ELISA kits, Human Diagnostics, } \\
\text { Germany }\end{array}$ \\
\hline $\begin{array}{l}\text { Chaudhary } \\
\text { et al, } \\
2013^{17}\end{array}$ & $\begin{array}{l}\text { Cross- } \\
\text { sectional }\end{array}$ & $\begin{array}{l}\text { Jan 2011- } \\
\text { Apr 2011 }\end{array}$ & NA & 92.7 & 2155 & NA & NA \\
\hline \multirow{3}{*}{$\begin{array}{l}\text { Ghafoor } \\
\text { et al, } \\
2016^{18}\end{array}$} & \multirow[t]{3}{*}{$\begin{array}{l}\text { Cross- } \\
\text { sectional }\end{array}$} & \multirow[t]{3}{*}{$\begin{array}{l}\text { Nov 2015- } \\
\text { Jan } 2016\end{array}$} & \multirow[t]{3}{*}{$(20-50)$} & \multirow[t]{3}{*}{94.67} & \multirow[t]{3}{*}{1500} & $\begin{array}{l}\mathrm{HBsAg} \text {, anti-HCV Abs, } \\
\text { anti-HIV Abs }\end{array}$ & ICT SD BIOLINE kits \\
\hline & & & & & & Anti-HIV-I, anti-HIV-2 Abs & Tri line HIV rapid test device \\
\hline & & & & & & $\begin{array}{l}\text { Treponema pallidum IgM } \\
\text { and IgG Abs }\end{array}$ & $\begin{array}{l}\text { Rapid Treponema pallidum/syphilis } \\
\text { test }\end{array}$ \\
\hline $\begin{array}{l}\text { Waheed } \\
\text { et al, } \\
2016^{19}\end{array}$ & Retrospective & $\begin{array}{l}\text { Jan } 2015- \\
\text { Dec } 2015\end{array}$ & NA & NA & 65,376 & $\begin{array}{l}\text { HIV, hepatitis B, hepatitis } \\
\text { C, syphilis, malarial } \\
\text { parasite }\end{array}$ & $\begin{array}{l}(n=44,538) \text { CIA, }(n=6524) \text { ELISA, } \\
(n=14,036) \text { NAT, }(n=560) \text { manual } \\
\text { devices }\end{array}$ \\
\hline $\begin{array}{l}\text { Sial et al, } \\
2016^{20}\end{array}$ & Observational & $\begin{array}{l}\text { Jan } 2011- \\
\text { Dec } 2013\end{array}$ & $\begin{array}{l}27.8 \\
(17-50)\end{array}$ & 90.4 & 29,522 & $\begin{array}{l}\mathrm{HBsAg} \text {, anti-HCV Abs, } \\
\text { anti-HIV Abs, syphilis }\end{array}$ & $\begin{array}{l}\mathrm{ClA} \text {, Architect Ci4100, Abbott } \\
\text { Diagnostic, USA }\end{array}$ \\
\hline
\end{tabular}

(Continued) 
Table I (Continued).

\begin{tabular}{|c|c|c|c|c|c|c|c|}
\hline $\begin{array}{l}\text { Author, } \\
\text { Year }\end{array}$ & Design & Duration & $\begin{array}{l}\text { Age in } \\
\text { Years } \\
\text { (Range) }\end{array}$ & $\begin{array}{l}\text { Male } \\
(\%)\end{array}$ & $\begin{array}{l}\text { No. of } \\
\text { Donors }\end{array}$ & Investigation & Diagnostic Methods \\
\hline \multirow[t]{4}{*}{$\begin{array}{l}\text { Raza et al, } \\
2016^{21}\end{array}$} & \multirow{4}{*}{$\begin{array}{l}\text { Cross- } \\
\text { sectional } \\
\text { observational }\end{array}$} & \multirow[t]{4}{*}{$\begin{array}{l}\text { Jul } 2014 \\
\text { Jun } 2016\end{array}$} & \multirow[t]{4}{*}{29.58} & \multirow[t]{4}{*}{ NA } & \multirow[t]{4}{*}{33,595} & \multirow[t]{2}{*}{$\begin{array}{l}\mathrm{HBsAg} \text {, anti-HCV Abs, } \\
\text { anti-HIV I/2 Abs }\end{array}$} & $\begin{array}{l}\text { CIA, Architect Ci2000, Abbott } \\
\text { Diagnostic, USA }\end{array}$ \\
\hline & & & & & & & $\begin{array}{l}\text { NAT, Cobas Taq screen MPX, } \\
\text { Roche Molecular Diagnostics }\end{array}$ \\
\hline & & & & & & Syphilis & $\begin{array}{l}\text { CIA, Architect Ci2000, Abbott } \\
\text { Diagnostic, USA }\end{array}$ \\
\hline & & & & & & Malarial parasite & ICT \\
\hline \multirow[t]{2}{*}{$\begin{array}{l}\text { Niazi et al, } \\
2016^{22}\end{array}$} & \multirow[t]{2}{*}{ Descriptive } & \multirow[t]{2}{*}{$\begin{array}{l}\text { Jan } 2010 \\
\text { Dec } 2012\end{array}$} & \multirow[t]{2}{*}{$\begin{array}{l}29 \\
(18-60)\end{array}$} & \multirow[t]{2}{*}{98.5} & \multirow[t]{2}{*}{160,552} & $\begin{array}{l}\mathrm{HBsAg} \text {, anti-HCV Abs, } \\
\text { anti-HIV Abs }\end{array}$ & $\begin{array}{l}\text { Architect i2000, Abbott } \\
\text { Diagnostics USA }\end{array}$ \\
\hline & & & & & & Anti-syphilis Abs & $\begin{array}{l}\text { Rapid ICT kit, InTec Products, Inc., } \\
\text { Xiamen }\end{array}$ \\
\hline \multirow{3}{*}{$\begin{array}{l}\text { Nadeem } \\
\text { et al, } \\
2016^{23}\end{array}$} & \multirow[t]{3}{*}{ Descriptive } & \multirow[t]{3}{*}{$\begin{array}{l}\text { Jun } 2012- \\
\text { May } 2013\end{array}$} & \multirow[t]{3}{*}{$\begin{array}{l}33 \\
(18-60)\end{array}$} & \multirow[t]{3}{*}{99.4} & \multirow[t]{3}{*}{4662} & $\begin{array}{l}\text { HBsAg, anti-HCV Abs, } \\
\text { anti-HIV Abs }\end{array}$ & ELISA \\
\hline & & & & & & Syphilis & RPR \\
\hline & & & & & & Malarial parasite & $\begin{array}{l}\text { Biotech Immunochromatographic } \\
\text { (ICT) }\end{array}$ \\
\hline \multirow{2}{*}{$\begin{array}{l}\text { Arshad } \\
\text { et al, } \\
2016^{24}\end{array}$} & \multirow[t]{2}{*}{ Prospective } & \multirow[t]{2}{*}{$\begin{array}{l}\text { Jan } 2013- \\
\text { Jun } 2015\end{array}$} & \multirow[t]{2}{*}{$\begin{array}{l}28.6 \\
(18-55)\end{array}$} & \multirow[t]{2}{*}{99.7} & \multirow[t]{2}{*}{16,602} & $\begin{array}{l}\text { HBsAg, anti-HCV Abs, } \\
\text { anti-HIV Abs, syphilis }\end{array}$ & $\begin{array}{l}\text { CIA, Architect Ci2000, Abbott } \\
\text { Diagnostic, USA }\end{array}$ \\
\hline & & & & & & Malarial parasite & $\begin{array}{l}\text { Thick films and } \\
\text { Immunochromatographic (ICT) }\end{array}$ \\
\hline \multirow{3}{*}{$\begin{array}{l}\text { Memon } \\
\text { et al, } \\
2017^{25}\end{array}$} & \multirow{3}{*}{$\begin{array}{l}\text { Cross- } \\
\text { sectional } \\
\text { descriptive }\end{array}$} & \multirow[t]{3}{*}{$\begin{array}{l}\text { Jan } 2014- \\
\text { Jun } 2015\end{array}$} & \multirow[t]{3}{*}{ NA } & \multirow[t]{3}{*}{ NA } & \multirow[t]{3}{*}{4683} & $\begin{array}{l}\mathrm{HBsAg} \text {, anti-HCV Abs, } \\
\text { anti-HIV Abs }\end{array}$ & $\begin{array}{l}\text { CIA, Architect Ci2000, Abbott } \\
\text { Diagnostic, USA }\end{array}$ \\
\hline & & & & & & Syphilis & $\begin{array}{l}\text { ICT device with ABON Biopharm } \\
\text { (Hangzhou) kit }\end{array}$ \\
\hline & & & & & & Malarial parasite & $\begin{array}{l}\text { Thick and thin smear using } \\
\text { Romanowsky stain }\end{array}$ \\
\hline $\begin{array}{l}\text { Zameer } \\
\text { et al, } \\
2017^{26}\end{array}$ & Descriptive & $\begin{array}{l}\text { Oct 2015- } \\
\text { Feb } 2016\end{array}$ & $(18-55)$ & NA & 10,048 & $\begin{array}{l}\mathrm{HBsAg} \text {, anti-HCV Abs, } \\
\text { anti-HIV Abs, syphilis, } \\
\text { malarial parasite }\end{array}$ & ICT \\
\hline $\begin{array}{l}\text { Wadood } \\
\text { et al, } \\
2017^{27}\end{array}$ & Prospective & $\begin{array}{l}\text { Jun } 2015- \\
\text { May } 2016\end{array}$ & NA & 97 & 536 & Anti-HCV Abs & Third-generation ELISA \\
\hline $\begin{array}{l}\text { Saeed et al, } \\
2017^{28}\end{array}$ & Prospective & $\begin{array}{l}\text { Dec 2014- } \\
\text { Nov } 2015\end{array}$ & $(19-59)$ & 99.32 & 18,274 & $\begin{array}{l}\mathrm{HBsAg} \text {, anti-HCV Abs, } \\
\text { anti-HIV Abs, syphilis } \\
\text { malarial parasite }\end{array}$ & ICT \\
\hline $\begin{array}{l}\text { Sultan et al, } \\
2017^{29}\end{array}$ & Prospective & $\begin{array}{l}\text { Feb 2015- } \\
\text { Feb } 2016\end{array}$ & 29.09 & 99.5 & 16,957 & $\begin{array}{l}\text { HBsAg, anti-HCV Abs, } \\
\text { anti-HIV Abs, syphilis }\end{array}$ & $\begin{array}{l}\text { CIA, Architect Ci2000, Abbott } \\
\text { Diagnostic, USA }\end{array}$ \\
\hline
\end{tabular}

(Continued) 
Table I (Continued).

\begin{tabular}{|c|c|c|c|c|c|c|c|}
\hline $\begin{array}{l}\text { Author, } \\
\text { Year }\end{array}$ & Design & Duration & $\begin{array}{l}\text { Age in } \\
\text { Years } \\
\text { (Range) }\end{array}$ & $\begin{array}{l}\text { Male } \\
(\%)\end{array}$ & $\begin{array}{l}\text { No. of } \\
\text { Donors }\end{array}$ & Investigation & Diagnostic Methods \\
\hline $\begin{array}{l}\text { Rehman } \\
\text { et al, } \\
2018^{30}\end{array}$ & $\begin{array}{l}\text { Cross- } \\
\text { sectional }\end{array}$ & NA & NA & NA & 1400 & Anti-HCV Abs & ICT and MEIA and ELISA \\
\hline \multirow[t]{3}{*}{$\begin{array}{l}\text { Raza et al, } \\
2018^{31}\end{array}$} & \multirow[t]{3}{*}{$\begin{array}{l}\text { Cross- } \\
\text { sectional }\end{array}$} & \multirow[t]{3}{*}{$\begin{array}{l}\text { Aug 2014- } \\
\text { Jul } 2015\end{array}$} & \multirow[t]{3}{*}{ NA } & \multirow[t]{3}{*}{ NA } & \multirow[t]{3}{*}{16,660} & \multirow[t]{2}{*}{$\begin{array}{l}\text { HBsAg, anti-HCV Abs, } \\
\text { anti-HIV Abs, syphilis }\end{array}$} & $\begin{array}{l}\text { CIA, Architect Ci2000, Abbott } \\
\text { Diagnostic, USA }\end{array}$ \\
\hline & & & & & & & $\begin{array}{l}\text { NAT, Cobas Taq screen MPX, } \\
\text { Roche Molecular Diagnostics }\end{array}$ \\
\hline & & & & & & Malarial parasite & $\begin{array}{l}\text { ICT, Rapid SD, Bioline, Korea and } \\
\text { Microscopic examination }\end{array}$ \\
\hline \multirow[t]{3}{*}{$\begin{array}{l}\text { Awan et al, } \\
2018^{32}\end{array}$} & \multirow{3}{*}{$\begin{array}{l}\text { Cross- } \\
\text { sectional } \\
\text { descriptive }\end{array}$} & \multirow[t]{3}{*}{$\begin{array}{l}\text { Jul 2015- } \\
\text { Oct } 2017\end{array}$} & \multirow[t]{3}{*}{$(18-60)$} & \multirow[t]{3}{*}{ NA } & \multirow[t]{3}{*}{30,470} & $\begin{array}{l}\mathrm{HBsAg} \text {, anti-HCV Abs, HIV } \\
\mathrm{I} / 2 \mathrm{Ab} / \mathrm{Ag}\end{array}$ & $\begin{array}{l}\text { Fully automated immunoassay } \\
\text { analyzer and triplex NAT PCR }\end{array}$ \\
\hline & & & & & & Treponema pallidum Abs & $\mathrm{ClA}$ \\
\hline & & & & & & Malarial parasite & ICT \\
\hline \multirow[t]{7}{*}{$\begin{array}{l}\text { Naz et al, } \\
2018^{33}\end{array}$} & \multirow[t]{7}{*}{$\begin{array}{l}\text { Cross- } \\
\text { sectional }\end{array}$} & \multirow[t]{7}{*}{$\begin{array}{l}\text { Jan } 2013- \\
\text { Jul } 2014\end{array}$} & \multirow[t]{7}{*}{$28.6 \pm 2$} & \multirow[t]{7}{*}{99.8} & \multirow[t]{7}{*}{14,652} & $\begin{array}{l}\text { HBsAg, anti-HIV Abs, } \\
\text { syphilis }\end{array}$ & $\mathrm{ClA}$, Architect, Abbot \\
\hline & & & & & & \multirow[t]{5}{*}{ Anti-HCV Abs } & Multisure HCV antibody assay \\
\hline & & & & & & & NAT, Artus RG RT-PCR kit \\
\hline & & & & & & & $\begin{array}{l}\text { ELISA, Monolisa }{ }^{\mathrm{TM}} \text { Anti-HCV Plus } \\
\text { V2 }\end{array}$ \\
\hline & & & & & & & Anti-HCV-MPBIO-EIA \\
\hline & & & & & & & MPD HCV blot 3.0 \\
\hline & & & & & & Malarial parasite & $\begin{array}{l}\text { Microscopy of Leishman's stained } \\
\text { blood films }\end{array}$ \\
\hline $\begin{array}{l}\text { Abdullah } \\
\text { et al, } \\
2019^{34}\end{array}$ & $\begin{array}{l}\text { Retrospective } \\
\text { cross- } \\
\text { sectional }\end{array}$ & $\begin{array}{l}\text { Jan 2016- } \\
\text { Dec } 2017\end{array}$ & $(19-60)$ & NA & 76,530 & $\mathrm{HBsAg}$ & Rapid test kits, Diagnostar \\
\hline $\begin{array}{l}\text { Rauf et al, } \\
2019^{35}\end{array}$ & Retrospective & $\begin{array}{l}\text { May 2018- } \\
\text { Feb } 2019\end{array}$ & 29 & 99.97 & 6594 & $\begin{array}{l}\text { HBsAg, anti-HCV Abs, } \\
\text { anti-HIV Abs, syphilis, } \\
\text { malarial parasite }\end{array}$ & CIA, Roche e6II \\
\hline \multirow[t]{2}{*}{$\begin{array}{l}\text { Masood } \\
\text { et al, }{ }^{36}\end{array}$} & \multirow[t]{2}{*}{ NA } & \multirow[t]{2}{*}{ NA } & \multirow[t]{2}{*}{ NA } & \multirow[t]{2}{*}{ NA } & \multirow[t]{2}{*}{8517} & \multirow[t]{2}{*}{$\mathrm{HBsAg}$} & $\begin{array}{l}\text { CIA, Architect Ci2000, Abbott } \\
\text { Diagnostic, USA }\end{array}$ \\
\hline & & & & & & & $\begin{array}{l}\text { PCR using type-specific primer } \\
\text { sequence }\end{array}$ \\
\hline $\begin{array}{l}\text { Ali et al, } \\
2010^{37}\end{array}$ & Prospective & NA & $(15-65)$ & 98.4 & 1558 & Malarial parasite & $\begin{array}{l}\text { Thick and thin blood smears with } \\
\text { Giemsa stain }\end{array}$ \\
\hline
\end{tabular}

(Continued) 
Table I (Continued).

\begin{tabular}{|c|c|c|c|c|c|c|c|}
\hline $\begin{array}{l}\text { Author, } \\
\text { Year }\end{array}$ & Design & Duration & $\begin{array}{l}\text { Age in } \\
\text { Years } \\
\text { (Range) }\end{array}$ & $\begin{array}{l}\text { Male } \\
(\%)\end{array}$ & $\begin{array}{l}\text { No. of } \\
\text { Donors }\end{array}$ & Investigation & Diagnostic Methods \\
\hline \multirow{2}{*}{$\begin{array}{l}\text { Usman } \\
\text { et al, } \\
2015^{38}\end{array}$} & \multirow[t]{2}{*}{ Prospective } & \multirow[t]{2}{*}{$\begin{array}{l}\text { May 2008- } \\
\text { Mar 2014 }\end{array}$} & \multirow[t]{2}{*}{ NA } & \multirow[t]{2}{*}{ NA } & \multirow[t]{2}{*}{87,600} & \multirow[t]{2}{*}{ Malarial parasite } & $\begin{array}{l}\text { Thick and thin blood smears with } \\
\text { Field's stain }\end{array}$ \\
\hline & & & & & & & $\begin{array}{l}\text { ICT test, PL-P MAL, Humasis, } \\
\text { Anyang, Korea }\end{array}$ \\
\hline $\begin{array}{l}\text { Ghani et al, } \\
2015^{39}\end{array}$ & Retrospective & $1998-2013$ & NA & NA & 626,413 & Anti-HIV Abs & $\begin{array}{l}\text { MEIA, Axsym system, till } 2007 \\
\text { then CIA, Architect i2000, Abbott } \\
\text { Diagnostic, USA }\end{array}$ \\
\hline \multirow{2}{*}{$\begin{array}{l}\text { Kousar } \\
\text { et al, } \\
2016^{40}\end{array}$} & \multirow[t]{2}{*}{ Observational } & \multirow{2}{*}{$\begin{array}{l}\text { Jul 2015- } \\
\text { Dec } 2015\end{array}$} & \multirow[t]{2}{*}{$(17-60)$} & \multirow[t]{2}{*}{99.9} & \multirow[t]{2}{*}{6000} & \multirow[t]{2}{*}{ Malarial parasite } & ICT \\
\hline & & & & & & & $\begin{array}{l}\text { Thick and thin blood smears with } \\
\text { Giemsa stain }\end{array}$ \\
\hline $\begin{array}{l}\text { Zahoor } \\
\text { et al, } \\
2020^{41}\end{array}$ & $\begin{array}{l}\text { Retrospective } \\
\text { cross- } \\
\text { sectional }\end{array}$ & $\begin{array}{l}\text { Jan } 2016- \\
\text { Dec } 2017\end{array}$ & NA & NA & 76,530 & Treponema pallidum Abs & $\begin{array}{l}\text { ICT, Nantong Egens Syphilis } \\
\text { detection Kits }\end{array}$ \\
\hline
\end{tabular}

Abbreviations: ELISA, enzyme-linked immunosorbent assay; RPR, rapid plasma regain; PCR, polymerase chain reaction; NAT, nucleic acid test; MEIA, microparticle enzyme immunoassay; NA, not available; Abs, antibodies; CIA, chemiluminescent immunoassay; ICT, immunochromatographic.

HIV,syphilis, and malaria) and cumulative frequency of TTIs was about $4 \%$ to $9 \%$ of all donors. $^{12,13,15,18-21,25,26,28,31}$ One study with $94 \%$ RDs reported the total frequency of TTIs to be $14.34 \%{ }^{11}$ Three studies with $100 \%$ VNRDs reported a significantly lower frequency of TTIs, i.e., 3.54\%, $4.9 \%$, and $6.2 \%{ }^{9,17,18}$ The frequency of TTI was significantly higher among RDs than in VNRDs in one study, $4.15 \%$ versus $0.48 \%{ }^{13}$ TTIs, mainly $\mathrm{HBV}$ and $\mathrm{HCV}$, were common causes of blood donation deferrals. ${ }^{15,23}$ Transfusion-related infections also resulted in discard of $5.01 \%$ of donated blood. ${ }^{19}$ As the majority of studies had a smaller number of female donors, TTI frequency was exceptionally low among females. ${ }^{12,13,17,22,24,29}$ One study with the highest population $(9.6 \%)$ of female donors (age range, 18-40, 67\% females were 20-30 years-old $)$ reported $22 \%(\mathrm{n}=366)$ of reactive female donors. ${ }^{20}$ Donors with a lower socioeconomic status had a higher frequency of TTIs. ${ }^{35}$ According to Raza et al., the majority of reactive donors $(69.5 \%)$ had a history of previous blood donations and had limited education. $^{31}$ When donors were educated it had a positive influence on their knowledge about TTIs. Odds of limited TTI knowledge were increased if donors had a secondary level of education versus tertiary level of education, OR: 4.04, CI: $1.567-10.435, \mathrm{p}<0.01 .^{31}$ Overall, $48 \%$ of donors in the study had no knowledge that they could transmit an infection through blood transfusion. Donors with secondary education had better attitudes toward BT compared to those with primary education, OR: 2.019 , CI: $1.190-3.426, \mathrm{p}<0.01 .^{31}$ The notification of reactive donors about a positive test was also very low, i.e., $54.25 \%$ of all positive cases. ${ }^{31}$ Major causes of a low notification rate were non-responses and failure to reach out to provided contact information. ${ }^{31}$

\section{Hepatitis B}

The frequency of hepatitis B (HBsAg) in donors ranged from $0.81 \%$ to $4.22 \%$. $^{9-15,17-26,28,29,31,32,34-36}$ Cumulative frequency calculated from 24 studies published between 2010 and 2020 was $2.04 \%(n=16,203)$ and 20 studies had HBV frequency below $2 \%$ while 4 studies had frequency above $2 \%{ }^{11,12,19,36}$ Attaullah et al. recorded an upward trend in the frequency of HBV from $2.60 \%$ in 2008 to $5.03 \%$ in $2011 .^{12}$ Abdullah et al., however, documented a downward trend in the frequency from $1.78 \%$ in 2016 to $1.51 \%$ in $2017 .{ }^{34}$ Sial et al recorded a higher HBV rate in males $(63 \%)$ versus females (27\%) but females accounted for $9.6 \%$ of all donors. ${ }^{20}$ Similarly, Niazi et al. calculated a higher frequency among males $(1.50 \%)$ versus females $(0.37 \%)$ with females representing $1.5 \%$ of the donors. ${ }^{22}$ Unmarried donors in one 
Table 2 Summary of Data from Studies Reporting the Frequency of Hepatitis B and Hepatitis C Among Blood Donors

\begin{tabular}{|c|c|c|c|c|c|}
\hline Study & $\begin{array}{l}\text { Number } \\
\text { of Donors }\end{array}$ & Type of Donors ${ }^{a}$ & $\begin{array}{l}\text { Frequency of } \\
\text { Hep B (HBsAg) }\end{array}$ & $\begin{array}{l}\text { Frequency of Hep } \\
\text { C (Anti-HCV Antibodies) }\end{array}$ & $\begin{array}{l}\text { Frequency of Hep B, } \\
\text { Hep C Coinfection }\end{array}$ \\
\hline Shah et $\mathrm{al}^{9}$ & 32,042 & VNRDs (100\%) & 632 (1.97\%) & 502 (1.57\%) & NR \\
\hline Ansari et al $^{10}$ & 5517 & NR & $104(1.8 \%)$ & $109(1.9 \%)$ & NR \\
\hline Waheed et al" & 10,145 & $\begin{array}{l}\text { RDs (94\%) } \\
\text { VNRDs (6\%) }\end{array}$ & 397 (3.91\%) & 846 (8.34\%) & NR \\
\hline Attaullah et $\mathrm{al}^{12}$ & $\mathrm{I}, 27,828$ & NR & 3432 (2.68\%) & 3147 (2.46\%) & NR \\
\hline Irfan et $\mathrm{al}^{13}$ & 108,598 & $\begin{array}{l}\text { RDs (98.8\%) } \\
\text { VNRDs (I.2\%) }\end{array}$ & 2068 (1.90\%) & $2832(2.61 \%)$ & 94 (0.084\%) \\
\hline Tunio et al ${ }^{14}$ & 2696 & NR & 49 (I.82\%) & 93 (3.45\%) & $2(0.074 \%)$ \\
\hline Tufail et al ${ }^{15}$ & 1833 & NR & $15(0.81 \%)$ & 57 (3.1\%) & NR \\
\hline Sulehri et al ${ }^{16}$ & 600 & NR & NR & $\begin{array}{l}0 \% \\
60(10 \%)^{c}\end{array}$ & NR \\
\hline Chaudhary et al ${ }^{17}$ & 2155 & VNRDs (100\%) & $21(1.3 \%)$ & 77 (3.6\%) & NR \\
\hline Ghafoor et al ${ }^{18}$ & 1500 & VNRDs (I00\%) & $22(1.47 \%)$ & $62(4.1 \%)$ & NR \\
\hline Waheed et al ${ }^{19}$ & 65,376 & $\begin{array}{l}\text { RDs (9I.75\%) } \\
\text { VNRDs (8.25\%) }\end{array}$ & 2765 (4.22\%) & $1083(1.65 \%)$ & NR \\
\hline Sial et $\mathrm{a}^{20}$ & 29,522 & $\begin{array}{l}\text { RDs (87\%) } \\
\text { VNRDs (13\%) }\end{array}$ & 368 (I.24\%) & 743 (2.5I\%) & $9(0.03 \%)$ \\
\hline Raza et $\mathrm{al}^{21}$ & 33,595 & NR & 554 (I.64\%) & 716 (2.1\%) & NR \\
\hline Niazi et al ${ }^{22}$ & 160,552 & $\begin{array}{l}\text { RDs }(95.4 \%) \\
\text { VNRDs (4.6\%) }\end{array}$ & 2385 (1.48\%) & 4194 (2.61\%) & NR \\
\hline Nadeem et $\mathrm{al}^{23}$ & 4662 & $\begin{array}{l}\text { VNRDs (I0.7\%) } \\
\text { Directed (85.7\%) }\end{array}$ & 58 (I.24\%) & $99(2.12 \%)$ & NR \\
\hline Arshad et $\mathrm{al}^{24}$ & 16,602 & RDs (95\%) & $290(1.7 \%)$ & 307 (1.84\%) & NR \\
\hline Memon et $\mathrm{al}^{25}$ & 4683 & NR & $66(1.4 \%)$ & 165 (3.52\%) & NR \\
\hline Zameer et $\mathrm{al}^{26}$ & 10,048 & NR & 160 (1.59\%) & 387 (3.75\%) & 12 (0.1 I\%) \\
\hline Wadood et $\mathrm{al}^{27}$ & 536 & NR & NR & 16 (2.99\%) & NR \\
\hline Saeed et $\mathrm{al}^{28}$ & 18,274 & $\begin{array}{l}\text { RDs (99.89\%). } \\
\text { VNRDs (0.10\%) }\end{array}$ & $210(1.10 \%)$ & 480 (2.62\%) & $22(0.12 \%)$ \\
\hline Sultan et $\mathrm{a}^{29}$ & 16,957 & $\begin{array}{l}\text { RDs }(99.2 \%) \\
\text { VNRDs }(0.7 \%)\end{array}$ & 301 (1.78\%) & 365 (2.15\%) & NR \\
\hline Rehman et $\mathrm{al}^{30}$ & 1400 & VNRDs (100\%) & NR & 26 (1.85\%) & NR \\
\hline Raza et $\mathrm{al}^{3 !}$ & 16,660 & NR & 278 (1.67\%) & 318 (1.91\%) & NR \\
\hline Awan et $\mathrm{al}^{32}$ & 30,470 & NR & $\begin{array}{l}322(1.06 \%)^{d} \\
10(0.03 \%)^{e}\end{array}$ & $\begin{array}{l}392(1.29 \%)^{d} \\
3(0.01 \%)^{e}\end{array}$ & $5(0.02 \%)$ \\
\hline $\mathrm{Naz}$ et $\mathrm{al}^{33}$ & 14,652 & $\begin{array}{l}\text { RDs (95\%) } \\
\text { VNRDs (5\%) }\end{array}$ & NR & $\begin{array}{l}229(1.563 \%)^{\mathrm{d}} \\
138(0.94 \%)^{\mathrm{e}}\end{array}$ & NR \\
\hline
\end{tabular}

(Continued) 
Table 2 (Continued).

\begin{tabular}{|c|c|c|c|c|c|}
\hline Study & $\begin{array}{l}\text { Number } \\
\text { of Donors }\end{array}$ & Type of Donors ${ }^{a}$ & $\begin{array}{l}\text { Frequency of } \\
\text { Hep B (HBsAg) }\end{array}$ & $\begin{array}{l}\text { Frequency of Hep } \\
\text { C (Anti-HCV Antibodies) }\end{array}$ & $\begin{array}{l}\text { Frequency of Hep B, } \\
\text { Hep C Coinfection }\end{array}$ \\
\hline Abdullah et $\mathrm{al}^{34}$ & 76,530 & NR & 1262 (1.65\%) & NR & NR \\
\hline Rauf et $\mathrm{al}^{35}$ & 6594 & VNRDs (I.12\%) & 74 (I.I2\%) & $214(3.24 \%)$ & I5 (0.22\%) \\
\hline Masood et $\mathrm{al}^{36}$ & 8517 & NR & $200(2.5 \%)$ & NR & NR \\
\hline Total frequency & & & $\begin{array}{l}16,203 / 791,356= \\
2.04 \%^{f}\end{array}$ & $17,660 / 723,497=2.44 \%^{\mathrm{f}}$ & \\
\hline
\end{tabular}

Notes: ${ }^{a}$ Types of donors were considered not reported if they did not characterize patients into replacement donors, paid donors, or voluntary non-remunerated donors. ${ }^{b}$ Routine lab test. ${ }^{c}$ ELISA. ${ }^{d}$ Serology. ${ }^{e}$ NAAT. ${ }^{f}$ Total frequency of a single TTI was calculated based on the total number of donors positive for a particular TTI such as HBV or $\mathrm{HCV}$ divided by the total number of donors screened for that TTI multiplied by 100.

Abbreviations: ELISA, enzyme-linked immunosorbent assay; KPK, Khyber Pakhtunkhwa; NAAT, nucleic acid amplification test; RD, replacement donors; NR, not reported; VNRDs, voluntary non-remunerated donors.

study were more likely to be reactive for HBsAg compared to married donors $(\mathrm{p}=0.001){ }^{24}$

\section{Hepatitis C}

The frequency of hepatitis $\mathrm{C}$ (anti-HCV antibodies) in donors ranged from $1.29 \%$ to $10 \%$. Cumulative frequency of $\mathrm{HCV}$ calculated from 26 studies was $2.44 \%(\mathrm{n}=17,660){ }^{9-33,35}$ Frequency of HCV was less than $2 \%$ in 8 studies, $9,10,19,24,30-33$ $2-4 \%$ in 15 studies, ${ }^{12-15,17,20-23,25-29,35}$ and above $4 \%$ in 3 studies. ${ }^{11,16,18}$ In 19 studies that investigated the reactivity of $\mathrm{HBV}$ and $\mathrm{HCV}$ within the same population, $\mathrm{HCV}$ was much more frequently detected than HBV. ${ }^{10,11,13-15,17,18,20-26,28,29,31,32,35}$ HCV was the second most common cause $(22.89 \%)$ of blood donation deferrals in one study. ${ }^{15}$ In another study, $\mathrm{HCV}$ detection was the first most common cause (28.61\%) of blood donation deferrals. ${ }^{23}$ Irfan et al and Tufail et al. noted a higher number of reactive $\mathrm{HCV}$ cases in younger donors (less than 40 years). ${ }^{13,15}$ The number of $\mathrm{HCV}$ cases in male donors was higher than female donors in two studies, $74 \%$ vs $26 \%$ and $99.3 \%$ vs $0.7 \%{ }^{20,22} \mathrm{HCV}$ related risk factors were dental treatments $(50 \%)$, traveling abroad (23.07\%), history of surgery (11.53\%) and blood transfusions in one study $(7.69 \%){ }^{30}$

\section{HIV}

The Frequency of HIV cases ranged between $0 \%$ and $0.18 \%$ in individual studies, with cumulative frequency equal to $0.038 \%$ $(\mathrm{n}=497)$ based on 18 studies. ${ }^{11-13,15,18-22,24-26,28,29,31,32,35,39}$ Two studies had $0 \%$ of HIV-reactive cases. ${ }^{2-11}$ Another two studies had HIV frequency of $0.02 \%(\mathrm{~N}=26)$ and $0.07 \%(\mathrm{n}=$ $20)$ of the screened population, all positive cases were men. ${ }^{20,22}$ Irfan et al. reported a low frequency $(0.10 \%)$ of HIVpositive cases but faced difficulty in following up on reactive cases. ${ }^{13}$ Among 30 reactive cases in this study, only a small number responded to follow-up calls, and 5 cases actually returned to the $\mathrm{BB}$ for a confirmatory test. All those who underwent a confirmatory test were reactive. ${ }^{13}$ There was a downward trend in HIV frequency from 2008 to 2011 in one study with an overall frequency of $0.06 \%{ }^{12}$ Another study published in 2014 found 16 HIV reactive cases $(0.0057 \%)$ between 1998 and 2006, and 50 reactive cases (0.014\%) between 2007 and 2013, showing an upward trend. ${ }^{39}$ The causes of HIV contraction in this study were heterosexual high-risk sexual behavior (65\%), intravenous drug use (39\%) and blood transfusions (12\%). The author reported "men who have sex with men - MSM" in only $1.5 \%$ of cases. ${ }^{39}$

\section{Syphilis}

The frequency of syphilis in blood donors was between $0.11 \%$ and $3.01 \%$ in 17 studies with a cumulative frequency of $1.1 \%(n=6974) .{ }^{11,12,18-26,28,29,31,32,35,41}$ Seven studies reported syphilis in less than $1 \%$ of the donors, ${ }^{11,12,18,19,22,23,32}$ six studies between $1 \%$ and $2 \%,{ }^{20,21,28,29,31,35}$ and four studies in more than $2 \%$ of donors. ${ }^{24-26,41}$ In one study, the author collected data from $19 \mathrm{BBs}, 6 \mathrm{BBs}$ did not routinely screen donors for syphilis and only $38 \%$ of all donations were screened for syphilis. ${ }^{19}$ Syphilis reactivity also led to the rejection of $10.4 \%$ of donors. ${ }^{23}$ In one study from Karachi, daily wage laborers and married donors were more likely to be syphilis reactive. ${ }^{24}$ Zahoor et al. noted an upward trend of syphilis cases between 2016 (2.02\%) to 2017 (2.46\%). These donors were referred to their center from all over Pakistan. ${ }^{41}$ Ghafoor et al.noted six out of seven (86\%) total cases of syphilis being above $40 .{ }^{18}$ Among 571 reactive syphilis donors reported by Sial et al., 93\% were men and the majority of reactive donors (54\%) 
Table 3 Summary of Data from Studies Reporting Frequency of HIV, Syphilis, and Malaria in Blood Donors

\begin{tabular}{|c|c|c|c|c|c|}
\hline Study & No. of Donors & Type of Donors ${ }^{a}$ & Frequency of HIV & Frequency of Syphilis & Frequency of Malaria \\
\hline Ali et $\mathrm{al}^{37}$ & 1558 & VNRDs (I00\%) & NR & NR & $9(0.577 \%)$ \\
\hline Waheed et al" & 10,145 & $\begin{array}{l}\text { RDs (94\%) } \\
\text { VNRDs (6\%) }\end{array}$ & $0 \%$ & $90(0.89 \%)$ & 121 (1.20\%) \\
\hline Ansari et $\mathrm{al}^{10}$ & 5517 & NR & $0 \%$ & NR & NR \\
\hline Attaullah et $\mathrm{al}^{12}$ & $1,27,828$ & NR & 77 (0.06\%) & $544(0.43 \%)$ & \\
\hline Irfan et $\mathrm{al}^{13}$ & 108,598 & $\begin{array}{l}\text { RDs }(98.8 \%) \\
\text { VNRDs }(1.2 \%)\end{array}$ & $1 \mathrm{II}(0.10 \%)$ & NR & NR \\
\hline Tufail et al ${ }^{15}$ & 1833 & NR & $3(0.16 \%)$ & NR & NR \\
\hline Ghafoor et al ${ }^{18}$ & 1500 & VNRDs (100\%) & $2(0.13 \%)$ & 7 (0.46\%) & NR \\
\hline Usman et $\mathrm{al}^{38}$ & 87,600 & NR & NR & NR & $38(0.04 \%)$ \\
\hline Ghani et $\mathrm{al}^{39}$ & 626,413 & NR & $66(0.01 \%)$ & NR & NR \\
\hline Waheed et al ${ }^{19}$ & 65,376 & $\begin{array}{l}\text { RDs (9I.75\%) } \\
\text { VNRDs (8.25\%) }\end{array}$ & $45(0.06 \%)$ & 71 (0.11\%) & $24(0.04 \%)$ \\
\hline Sial et $\mathrm{al}^{20}$ & 29,522 & $\begin{array}{l}\text { RDs (87\%) } \\
\text { VNRDs (I3\%) }\end{array}$ & $20(0.07 \%)$ & 531 (1.79\%) & NR \\
\hline Raza et $\mathrm{al}^{21}$ & 33,595 & NR & $34(0.10 \%)$ & $582(1.73 \%)$ & $2(0.005 \%)$ \\
\hline Niazi et al ${ }^{22}$ & 160,552 & $\begin{array}{l}\text { RDs }(95.4 \%) \\
\text { VNRDs }(4.6 \%)\end{array}$ & $26(0.02 \%)$ & $1520(0.95 \%)$ & NR \\
\hline Nadeem et $\mathrm{al}^{23}$ & 4662 & $\begin{array}{l}\text { VNRDs ( } 10.7 \%) \\
\text { Directed (85.7\%) }\end{array}$ & NR & $36(0.8 \%)$ & NR \\
\hline Arshad et $\mathrm{al}^{24}$ & 16,602 & RDs (95\%) & 7 (0.04\%) & $357(2.1 \%)$ & $12(0.07 \%)$ \\
\hline Kousar et $\mathrm{al}^{40}$ & 6000 & NR & NR & NR & $30(0.5 \%)$ \\
\hline Memon et $\mathrm{a}^{25}$ & 4683 & NR & $3(0.06 \%)$ & $|4|$ (3.0I\%) & $5(0.10 \%)$ \\
\hline Zameer et $\mathrm{al}^{26}$ & 10,048 & NR & $12(0.11 \%)$ & 209 (2.08\%) & $39(0.39 \%)$ \\
\hline Saeed et al ${ }^{28}$ & 18,274 & $\begin{array}{l}\text { RDs }(99.89 \%) \\
\text { VNRDs }(0.10 \%)\end{array}$ & $4(0.02 \%)$ & $284(1.55 \%)$ & $20(0.10 \%)$ \\
\hline Sultan et $\mathrm{al}^{29}$ & 16,957 & $\begin{array}{l}\text { RDs }(99.2 \%) \\
\text { VNRDs }(0.7 \%)\end{array}$ & $14(0.08 \%)$ & 287 (1.69\%) & $2(0.01 \%)$ \\
\hline Raza et $\mathrm{al}^{3 !}$ & 16,660 & NR & $12(0.07 \%)$ & $294(1.76 \%)$ & 2 (0.0।\%) \\
\hline Awan et $\mathrm{al}^{32}$ & 30,470 & NR & $49(0.16 \%)$ & $228(0.75 \%)$ & $5(0.02 \%)$ \\
\hline Rauf et $\mathrm{al}^{35}$ & 6594 & VNRDs (I.12\%) & $12(0.18 \%)$ & $73(1.10 \%)$ & 59 (0.89\%) \\
\hline Zahoor et $\mathrm{al}^{4 !}$ & 76,530 & NR & NR & $1720(2.25 \%)$ & NR \\
\hline Total frequency ${ }^{\mathrm{b}}$ & & & $497 / 1,291,167=0.038 \%^{b}$ & $6974 / 629,998=1.1 \%^{\mathrm{b}}$ & $368 / 309,562=0.11 \%^{\mathrm{b}}$ \\
\hline
\end{tabular}

Notes: ${ }^{a}$ Types of donors were considered not reported if they did not characterize patients into replacement donors, paid donors, or voluntary non-remunerated donors. ${ }^{\mathrm{b}}$ Total frequency for a single TTI was calculated based on the total number of donors positive for that TTI such as HIV, syphilis, or malaria divided by the total number of donors screened for that TTI multiplied by 100.

Abbreviations: ELISA, enzyme-linked immunosorbent assay; KPK, Khyber Pakhtunkhwa; NAAT, nucleic acid amplification test; RD, replacement donors; NR, not reported; VNRDs, voluntary non-remunerated donors. 
were between the age of 20 and $30 .{ }^{20}$ Similar to this, $99 \%$ of reactive donors were men in another study. ${ }^{22}$

\section{Malaria}

The frequency of malarial parasite ranged from $0.005 \%$ to $1.2 \%$ with a cumulative frequency of $0.11 \%(n=368)$ of all blood donors that were screened. ${ }^{11,19,21,24-26,28,29,31,32,35,37,38,40}$ All studies had a frequency of malaria less than $1 \%$ except one study by Waheed et al. with a frequency of $1.20 \% .{ }^{11}$ The malarial parasite was not routinely screened by six BBs in one study and only $46 \%$ of blood donations were screened. ${ }^{19}$ Malaria was the least frequently detected TTI in those studies that screened donors for all major types of TTIs. According to a WHO report, the prevalence of malaria was $0.1 \%, 1.78 \%$ and $0.81 \%$ for the years 2011, 2012 and 2013 in Pakistan. ${ }^{44}$

\section{Coinfections}

Co-infectivity has also been reported in many studies. Arshad et al. found $0.35 \% \quad(n=58)$ of donors with coinfections. ${ }^{24}$ Another study from Islamabad reported a very low frequency of co-infections, $0.039 \%(\mathrm{n}=12){ }^{32}$ Zameer et al. found $0.29 \%(n=29,28$ donors had 2 TTIs while 1 donor had 3 TTIs) cases of coinfections. The highest number of coinfections $(n=13)$ were $\mathrm{HCV}$ and syphilis followed by HCV and HBV $(n=12) .{ }^{26}$ One study from Lahore documented $0.38 \%(\mathrm{n}=71)$ of donors with coinfections; $\mathrm{HCV}$ and syphilis co-infectivity was the highest $(n=46)$ followed by HBV and HCV coinfections $(n=22) .{ }^{28}$ Another author reported a total co-infectivity of $0.09 \%(\mathrm{n}=103)$ with the highest co-infectivity seen with HBV and HCV in 94 cases. ${ }^{13}$ Sial et al. reported coinfections in $0.135 \%$ donors $(n=400)$ with HCV and syphilis having the highest co-infectivity in this study, $0.09 \%$ $(\mathrm{n}=27) .{ }^{20}$ Rauf et al. reported 15 cases $(0.22 \%)$ of HBV and $\mathrm{HCV}$ coinfections as the highest co-infectivity. ${ }^{35}$ Alarmingly, they reported 11 donors $(0.16 \%)$ who were concomitantly reactive for HBV, HCV, HIV and syphilis. ${ }^{35}$ Three concomitant TTIs were also reported in two donors by another author. ${ }^{13}$

\section{Discussion}

Pakistan has a poorly regulated, demand-driven fragmented BT system based on more than 1800 public hospitalbased or free-standing private blood banks (BBs). ${ }^{42,43}$ These units provide all services of the vein-to-vein transfusion chain, ranging from typing, cross-matching, donor screening, collection, storage and distribution of blood to the patients. There is inadequate initial screening of donors for high-risk behaviors due to inadequate training of BB staff. Limited knowledge of donors about their health and medical problems also increases the risk of TTIs. Pakistan lacks a universal quality-assured serological screening process. In many blood banks, poor quality, cheap and rapid manual methods are being used for quick screening along with poor laboratory practices. ${ }^{44}$ This can lead to a significant probability of missing an infection in the donor population with a multifold increased risk of transmission to transfusion recipients. Rates of voluntary donations are meager accounting for less than $13 \%$ of all donations. This is due to a lack of infrastructure, poor educational status and cultural beliefs of the general population. $^{45}$

According to a global status report (2016) by the WHO on blood safety and availability, the proportion of donations that screened TTIs in Pakistan were $100 \%$ for HIV, HBV, HCV and only $66 \%$ for syphilis and malaria. ${ }^{42}$ The seroprevalence of $\mathrm{HBV}$ in blood donors varied from $1.55 \%$ to $3.76 \%$, HCV from $2.55 \%$ to $7.23 \%$, HIV from $0.01 \%$ to $0.04 \%$ and syphilis varied from $0.59 \%$ to $1.16 \% \%{ }^{42-47}$

Our review showed a cumulative frequency of $2.04 \%$ $(n=16,203)$ for $\mathrm{HBV}$ and $2.44 \%(n=17,660)$ for $\mathrm{HCV}$ among blood donors. Transmission of $\mathrm{HBV}$ and $\mathrm{HCV}$ through blood transfusion is a significant concern. Pakistan falls in a low-intermediate prevalence area for $\mathrm{HBV}$, with an estimated carrier rate of $2-4 \%$ and an estimated 5 million individuals with chronic HBV infection. It has the second-largest number of HCV infected population worldwide. ${ }^{48}$ According to one estimate, almost 10 million people in the country are infected with chronic $\mathrm{HCV}$, that being roughly $5.9 \%$ of the total population. There is a high prevalence of $\mathrm{HCV}(48.67 \%)$ in chronically transfusion-dependent thalassemia and hemophilia patients. ${ }^{49}$ High prevalence of $\mathrm{HBV}$ and $\mathrm{HCV}$ in donors may be contributing to this high prevalence in the general population and among chronic transfusion recipients. WHO recommends donor screening of HCV through anti-HCV antibodies by rapid diagnostic immunoassay in resource-limited countries or a combination of HCV antigen-antibody immunoassay (EIA/CLIA). Samples reactive by CLIA/EIA should be further confirmed by nucleic acid amplification technology (NAT), which is the gold standard for HCV diagnosis. For HBV, blood donors should be screened using a highly sensitive and specific HBsAg 
immunoassay (EIA/CLIA). Routine screening for anti$\mathrm{HBc}$ for transfusion purposes is not needed. ${ }^{50}$

The concern of HIV spread is growing in the public health community of Pakistan. There are recent reports of isolated low-scale epidemics of HIV in rural areas. ${ }^{51}$ Pakistan is one of the countries located in the WHO Eastern Mediterranean Region and HIV infections are spreading at an alarming rate in this region. ${ }^{51}$ WHO considers the current HIV epidemic in Pakistan to be a concentrated one. The total prevalence of HIV is still less than $1 \%$ of the total adult population in Pakistan. ${ }^{51}$ According to the UNAIDS 2018 report, there is an alarming increase of $57 \%$ in new HIV cases and a $369 \%$ increase in AIDS-related deaths since $2010 .^{52}$ In 2018, only $14 \%$ of people living with HIV in Pakistan knew their HIV status. ${ }^{52}$ Given the lack of a centralized hemovigilance system, it is challenging to estimate a real-time risk of HIV infection in Pakistan due to BT. According to one article, the spread of HIV through blood transfusion in Pakistan was about $11.73 \%{ }^{53}$ Seroconversion to HIVpositive could be as high as $98 \%$ after exposure to HIV infected blood products. ${ }^{54}$ In developed countries such as the United States, the risk of contracting an HIV infection through transfusion is expected to be one in 1.5 million donations. ${ }^{55}$ The rate of HIV infectivity with packed red blood cells is inversely related to its storage time. HIV infected blood products which are stored for less than 8 days are $96 \%$ infectious. Infectivity drops to $50 \%$ when stored for more than 3 weeks. $^{54}$ There is a steady increase in the prevalence of HIV in the donor population. On the other hand, there is a lack of standardized HIV donor screening. The cumulative frequency of HIV in our study was $0.038 \%$ $(n=497)$.

An estimated 12 million new cases of syphilis are diagnosed each year globally, with an estimated global prevalence of $0.5 \%$ in men aged $15-49$ years. ${ }^{56,57}$ In our review, the cumulative frequency of syphilis in the donor population was $1.1 \%(\mathrm{n}=6974)$. Treponema pallidum is a relatively fragile bacterium which is sensitive to cold temperature and the risk of its transmission through BT is minimal if blood is stored below $20^{\circ}$ centigrade for longer than 72 hours. ${ }^{58,59}$ However, in Pakistan, most transfusions are stored for less than 72 hours due to arrangement by family members on a needed basis. WHO recommends testing with Venereal Disease Research Laboratory (VDRL), rapid plasma reagin (RPR) and cold storage techniques to minimize the risk of syphilis through transfusion. ${ }^{60}$

Malaria is endemic in Pakistan with 3.5 million cases every year. ${ }^{61}$ In our review, we noticed a lack of universal screening of blood for malaria. According to the Federal Drug Administration (FDA) and the American Association of Blood Bank (AABB), people with malaria cannot donate blood for 3 years after becoming asymptomatic. ${ }^{62,63}$ Rate of malaria transmission in endemic countries such as Pakistan may be as high as 50 cases per million blood donations. ${ }^{64}$ In our review, the cumulative frequency of malaria in blood donors was $0.11 \%(n=368)$. This seems to be an underestimation of the overall risk of transfusion-transmitted malaria due to a lack of uniform widespread testing protocols. The peripheral smear is the most widely used diagnostic test in Pakistan, but it is highly dependent on user technical skills and knowledge. ${ }^{64}$ Asymptomatic blood donors have low levels of parasite count along with the low density of parasite in the blood which can lead to difficulty in the detection of the parasite. ${ }^{65}$ The most effective way of screening donors is to take a proper history for any underlying disease, medications use, fever and highrisk exposure. ${ }^{8}$ Donor criteria should be developed locally and implemented to exclude potentially high-risk individuals.

According to the WHO, the number of total blood donations and VNRDs decrease steeply from highincome countries to low-income countries. ${ }^{66}$ Proportions of VNRDs in 2013 in high-income, upper-middle-income, lower-middle-income and low-income countries were $95 \%, 79 \%, 71 \%$ and $63 \%$, respectively. ${ }^{42}$ Therefore, there is limited access to safe blood, especially in lowincome countries. WHO recommends blood donations to be collected mainly from VNRDs because of their lowest prevalence of TTIs. ${ }^{66}$ Replacement/family donors (RDs) and paid (professional) or remunerated donors are less desirable than other types. With the aim of sufficient and sustainable blood supply, WHO envisions $100 \%$ of blood donations to be collected from VNRDs worldwide. ${ }^{67}$ Contrarily, almost $85-90 \%$ of blood donations came from RDs in Pakistan in 2011-2013. ${ }^{42}$ Despite efforts to decrease RDs and increase VNRDs, replacement donors accounted for $87 \%$ to $99.98 \%$ of all donors according to these studies. ${ }^{11,13,19,20,22,24,28,29,33}$ According to a global status report of the WHO, less than $25 \%$ of Pakistan's blood donations are by VNRDs. Development of the VNRDs-based collection system as recommended by the WHO is an important measure to ensure the availability of 
safe blood products. ${ }^{42}$ In Pakistan, there is a need for donor education and registration campaigns for the development of voluntary donor base, registration of family RDs for future voluntary donations and development of a network of BBs that rely on voluntary donations only.

Establishment of a separate qualification and training program of transfusion medicine in Pakistan can help implement standardization of quality metrics and assurance of safe blood supply. It provides a skilled workforce that can implement good evidence-based transfusion practices. ${ }^{68}$ WHO proposes the development of programs for integration of transfusion medicine education into the existing structure of medicine, nursing and laboratory technology institutions. ${ }^{69}$

Hemovigilance is a concept of surveillance of the whole vein-to-vein transfusion chain. It includes followups with transfusion recipients, collection and assessment of the data on unexpected or undesirable events related to the therapeutic use of blood products. It utilizes this information to prevent the occurrence or recurrence of such incidents in the future. ${ }^{70}$ In developing countries, it can help to assess the risk of TTIs. There are challenges to achieve effective hemovigilance in Pakistan due to limited availability of TTIs epidemiology data, lack of a centralized reporting system for adverse events and follow-up services for donors and recipients. There is suboptimal donor testing which leads to missing the infections due to high falsenegative results. ${ }^{71,72}$ Moreover, there is no mechanism for identifying the rate of transfusion-related infections in the general population. During our review, we were unable to find any large-scale surveillance and reporting data on TTIs.

The government of Pakistan has much more to do, but in 2010, they launched a series of initiatives, per the WHO guidelines, for an overall improvement of the BT system through national safe blood transfusion programs (SBTP). This led to the formulation of a national blood policy and strategic framework for the strengthening of the organizational structure of the transfusion system in Pakistan. Through the USAID, the WHO supplied blood-screening kits worth 84 million dollars. ${ }^{73}$ There are considerable improvements regarding the development of regional public blood centers with accreditation standards, improved data collection and implementation of universal screening guidelines. There are training and educational opportunities devoted to improving the quality, data collection and evidence-based blood use. But these efforts are mainly centered in major urban institutions with limited outreach to rural areas where the problem is severe and needs urgent intervention and attention.

This review has limitations because we based the review on the data from studies focused on localized geographical locations due to lack of availability of large scale-multicenter structured data. We relied on data sources to find the most recent and consistent information that could lead to inherent reporting bias for studies and their ability to be published. Most of the studies are of variable quality and scope. The donor populations also vary among studies and comparison of the population among studies is difficult due to the inconsistency of information and data provided. The screening methods differ among studies and there is variable sensitivity and specificity of the methods. There is a risk of missing or omitting some publications due to reviewer bias. The use of grey literature like the WHO and local reports is also based on limited data and rely on information reported by the government agencies. Our study represents the best possible overview of the underlying problem with limitations. We recommend large multi-centered studies involving rural centers in Pakistan.

\section{Conclusion}

Our study shows the cumulative frequency of HBV of $2.04 \%$, HCV of $2.44 \%$, HIV of $0.038 \%$, syphilis of $1.1 \%$ and malaria of $0.011 \%$ among screened donors. There is limited screening of syphilis (38\%) and malaria (46\%) in the donor population. The rate of co-infections is $0.35 \%$, with $\mathrm{HCV}$ and syphilis as the most frequent co-infections. The blood donors in Pakistan are mostly RDs and the rate of VNRDs is low $(0.10 \%-13 \%)$. There is a lack of widespread standardized testing and follow-up of donors who test positive on initial screening. Our findings highlight the need for promoting a culture of voluntary blood donations by creating awareness among the public to mobilize and motivate through media, professional medical societies, political factors, local governmental and nongovernmental organizations. Moreover, our data endorse the need for a universal quality-assured donor screening, development of a hemovigilance system, uniform standard operating procedures and a trained workforce for BBs. There is a need for large prospective multi-center epidemiological studies in the country for a better understanding of the burden of TTIs, impact of testing procedures and influence of mitigation strategies such as hemovigilance system and TTI tracking networks. 


\section{Disclosure}

The authors declare no conflicts of interest with this manuscript.

\section{References}

1. WHO model lists of essential medicines. World Health Organization; 2019. Available from: https://www.who.int/medicines/publications/ essentialmedicines/en. Accessed August 16, 2020.

2. Saqlain N, Ahmed N, Ahmed A, Hareem S. Blood donation; knowledge, attitude and beliefs of the female attendants. Professional Med J. 2017;24(12):1806-1811. doi:10.17957/TPMJ/17.4003

3. Pakistan SBTPGo. National blood banks data collection report 2018. Available from: https://www.sbtp.gov.pk/wp-content/uploads/2019/10/ National-Data-Collection-Report-2018.pdf. Accessed August 16, 2020.

4. Farhat M, Yasmeen A, Ahmad A. An overview of hepatitis B and C in Pakistan. Int J Microbiol Allied Sci. 2014;1:98-102.

5. Zaheer HA, Waheed U, Nasir K Safe blood transfusion programme annual report 2019 2019. Available from: https://www. sbtp.gov.pk/wp-content/uploads/2020/02/Final-Report-2019.pdf. Accessed August 16, 2020.

6. Muazzam A, Javed S. Predictors of caregiver's burden: interplay of physical and emotional health and perceived hope in children with thalassemia and hemophilia. Pak J Soci Clin Psychol. 2013;11(2):36.

7. Pasha O, Saleem S, Ali S, et al. Maternal and newborn outcomes in Pakistan compared to other low and middle income countries in the Global Network's Maternal Newborn Health Registry: an active, community-based, pregnancy surveillance mechanism. Reprod Health. 2015;12(S2):S15. doi:10.1186/1742-4755-12-S2-S15

8. WHO. Universal access to safe blood transfusion 2007. Available from: https://www.who.int/bloodsafety/StrategicPlan20082015AccessSafeBloodTransfusion.pdf. Accessed August 16, 2020.

9. Shah SM, Khattak IU, Ali A, Tariq M. Seropositivity for hepatitis $\mathrm{B}$ and $\mathrm{C}$ in voluntary blood donors. J Ayub Med Coll Abbottabad. 2010;22(3):149-151.

10. Ansari SH, Shamsi TS, Khan MT, et al. Seropositivity of Hepatitis C, Hepatitis B and HIV in chronically transfused $\beta \beta$-thalassaemia major patients. J Coll Physicians Surg Pak. 2012;22(9):610-611.

11. Waheed U, Khan H, Satti HS, Ansari MA, Malik MA, Zaheer HA. Prevalence of transfusion transmitted infections among blood donors of a teaching hospital in Islamabad. Ann Pak Inst Med Sci. 2012;8 (4):236-239.

12. Attaullah S, Khan S, Khan J. Trend of transfusion transmitted infections frequency in blood donors: provide a road map for its prevention and control. J Transl Med. 2012;10(1):20. doi:10.1186/ 1479-5876-10-20

13. Irfan SM, Uddin J, Zaheer HA, Sultan S, Baig A. Trends in transfusion transmitted infections among replacement blood donors in Karachi, Pakistan. Turk J Hematol. 2013;30(2):163. doi:10.4274/Tjh.2012.0132

14. Tunio SA, Bano S, Laghari ZA, Ali W, Shamim H, Afreen U. Seroprevalence of hepatitis B and hepatitis $\mathrm{C}$ among blood donors in Hyderabad, Pakistan. Gomal J Med Sci. 2013;11(2).

15. Tufail S, Babar F, Ikram N, Raza M, Abdul-Shakoor H. Blood donors' deferral-causes. J Rawalpindi Med Coll. 2013;17(1):119-121.

16. Sulehri MA, Hussain SJ, Mehmood Q, Javed SH. Incidence of false sero-negative blood donor cases for Hepatitis-C in public and private hospitals of city district Faisalabad. Ann Punjab Med Coll. 2013;7 (1):10-16.

17. Chaudhry MA, Malik JR, Ashraf MZ. Seropositivity of hepatitis $\mathrm{B}$ and $\mathrm{C}$ in blood donors at CMH Lahore, Pakistan. Ann Punjab Med Coll. 2013;7(1):1-5.

18. Ghafoor B, Hussain M, Leghari AR, Mehwish A, Zulfiqar S, Mustafa G. Major transfusion-transmissible infections among blood donors in Rahim Yar Khan, a district of Southern Punjab, Pakistan. Isra Med J. 2016;8(4).
19. Waheed U, Hasan SI, Wazeer A, Zaheer HA. The status of blood safety in Islamabad, Pakistan. Ann PIMS. 2016;12(4):209.

20. Sial GR, Khan S, Shahid SU, Bhatti S, Farooq F. Prevalence of transfusion transmitted infections in asymptomatic blood donors: is Syphilis alarming? Biomedica. 2016;32(1).

21. Raza N. Revisiting reactive blood donor demographics-A single center experience. J Liaquat Univ Med Health Sci. 2016;15:208-212.

22. Niazi SK, Mahmood A, Alam M, Ghani E. Seroprevalence of transfusion transmissible infections in blood donors: a three-year experience. Pak Armed Forces Med J. 2016;66(2):190-193.

23. Nadeem A, Salamat N, Iqbal N, et al. Demographic features of donors and causes of blood donor deferral at Armed Forces Institute of Transfusion, Rawalpindi. Pak Armed Forces Med J. 2016;66(6):898-902.

24. Arshad A, Borhany M, Anwar N, et al. Prevalence of transfusion transmissible infections in blood donors of Pakistan. BMC Hematol. 2016;16(1):27. doi:10.1186/s12878-016-0068-2

25. Memon FA, Ujjan ID, Memon AI, Shaikh AR, Rao AR, Naz A. Seroprevalence of transfusion transmitted infections among different blood group donors at Blood Bank LUMHS, Hyderabad. Pak J Med Sci. 2017;33(2):443. doi:10.12669/pjms.332.11691

26. Zameer M, Shahzad F, Khan FS, Ali H, Saeed U, Farooq M. Transfusion transmissible infections among healthy blood donors at blood bank from Children's Hospital \& Institute of Child Health Lahore. Pak Armed Forces Med J. 2017;1(1):131.

27. Maeesa W, Muhammad U, Khansa Q, Muhammad R, Iram N. Seroprevalence of hepatitis $\mathrm{C}$ among the apparently healthy blood donors of Karachi. Baqai J Health Sci. 2017;20(1):19-24.

28. Saeed M, Hussain S, Rasheed F, Ahmad M, Arif M, Rahmani MT. Silent killers: transfusion transmissible infections-TTI, among asymptomatic population of Pakistan. J Pak Med Assoc. 2017;67(3):369-374.

29. Sultan S, Nasir MI, Rafiq S, Baig MA, Akbani S, Irfan SM. Multiplex real-time RT-PCR assay for transfusion transmitted viruses in sero-negative allogeneic blood donors: an experience from Southern Pakistan. Malays J Pathol. 2017;39(2):149.

30. Rehman N, Orakzai MB, Hayat A, et al. Prevalence of Hepatitis $\mathrm{C}$ virus and its risk factors in blood donors in district Peshawar. Pak J Pharm Sci. 2018;31(1):83-87.

31. Raza N, Qureshi H, Qureshi A. Reactive blood donor notification; their responses and perceptions: experience from southern Pakistan. J Ayub Med Coll Abbottabad. 2018;30(3):351-355.

32. Awan SA, Junaid A, Sheikh S. Transfusion transmissible infections: maximizing donor surveillance. Cureus. 2018;10(12).

33. Naz A, Mukry SN, Naseer I, Shamsi TS. Evaluation of efficacy of serological methods for detection of HCV infection in blood donors: A single centre experience. Pak J Med Sci. 2018;34(5):1204.

34. Abdullah S, Zahoor S, Rao MA, et al. Seroprevalence of hepatitis $\mathrm{B}$ virus in blood donors at a large teaching hospital of Pakistan: a potential health policy concern. J Appl Hematol. 2019;10(1):29. doi:10.4103/joah.joah_10_19

35. Rauf R, Cheema A. Potential risk of transfusion-transmissible infections among blood donors in district Faisalabad of Pakistan. Clin Med (Northfield Il). 2019;19(Suppl 3):27. doi:10.7861/clinmedicine.19-3-s27

36. Masood I, Usman Waheed MA, Saeed M, et al. Molecular epidemiology of hepatitis B virus genotypes in blood donors in Islamabad, Pakistan. J Lab Physicians. 2019;11(3):240. doi:10.4103/JLP.JLP_150_18

37. Ali N, Ahmed J, Ali N, Jehan F, Saleem S. Transfusion transmitted malaria in three major blood banks of Peshawar, Pakistan. Afr J Biotechnol. 2010;9(33).

38. Usman M, Mahmood H. Frequency of malarial parasite infection in healthy blood donors of Pakistan. Baqai J Health Sci. 2015;18(1).

39. Ghani E, Rathore MA, Khan SA. Trends in human immunodeficiency virus seroprevalence in blood donors in northern Pakistan. Public Health. 2016;131:71-74. doi:10.1016/j.puhe.2015.10.010

40. Kousar R, Saqlain N, Ahmed N. Malarial parasite screening in blood donors; experience at the Children's Hospital \& Institute of Child Health, Lahore. Pak Pediatr J. 2016;40(3):143-147. 
41. Zahoor S, Hameed S, Iqbal W, ur Rehman H, ur Rehman N, Jaral J. Seroprevalence of Syphilis in healthy blood donors of Lahore during year 2016 and 2017; An upcoming problem for Pakistan. Professional Med J. 2020;27(01):138-142. doi:10.29309/TPMJ/2019.27.01.3823

42. Global status report on blood safety and availability 2016. Global database on blood safety. World Health Organization. Available from: https://apps.who.int/iris/bitstream/handle/10665/254987/ 9789241565431-eng.pdf? sequence=1. Accessed August 16, 2020.

43. Zaheer HA, Waheed U. Blood safety system reforms in Pakistan. Blood Transfus. 2014;12(4):452-457.

44. Waheed U, Abdella YE, Saba NE, et al. Evaluation of screening effectiveness of hepatitis B surface antigen and anti-HCV rapid test kits in Pakistan. J Lab Physicians. 2019;11(4):369-372. doi:10.4103/JLP. JLP_172_19

45. Mumtaz Z, Bowen S, Mumtaz R. Meanings of blood, bleeding and blood donations in Pakistan: implications for national vs global safe blood supply policies. Health Policy Plan. 2012;27(2):147-155. doi:10.1093/heapol/czr016

46. Waheed U, Arshad M, Usman J, Farooq A, Wazeer A, Zaheer HA. Surveillance of HIV infection in blood donors in Pakistan: a systematic review. Pak Armed Forces Med J. 2017;67(5):860-867.

47. Jefferies M, Rauff B, Rashid H, Lam T, Rafiq S. Update on global epidemiology of viral hepatitis and preventive strategies. World J Clin Cases. 2018;6(13):589-599. doi:10.12998/wjcc.v6.i13.589

48. Gower E, Estes C, Blach S, Razavi-Shearer K, Razavi H. Global epidemiology and genotype distribution of the hepatitis $\mathrm{C}$ virus infection. J Hepatol. 2014;61(1):S45-S57. doi:10.1016/j.jhep.2014.07.027

49. Waheed Y, Shafi T, Safi SZ, Qadri I. Hepatitis C virus in Pakistan: a systematic review of prevalence, genotypes and risk factors. World $J$ Gastroenterol. 2009;15(45):5647. doi:10.3748/wjg.15.5647

50. WHO. Screening donated blood for transfusion transmissible infections 2010. Available from: https://www.who.int/bloodsafety/ ScreeningDonatedBloodforTransfusion.pdf. Accessed August 16, 2020

51. WHO. HIV cases-Pakistan; July 2019. Available from: https://www.who. int/csr/don/03-july-2019-hiv-cases-pakistan/en/. Accessed August 16, 2020 .

52. UNAIDS. Country factsheets PAKISTAN 2018. Available from: https://www.unaids.org/en/regionscountries/countries/pakistan. Accessed August 16, 2020.

53. Bhurgri Y. HIV/AIDS in Pakistan. J Pak Med Assoc. 2006;56(1):1.

54. Donegan E, Lee H, Operskalski E, et al. Transfusion transmission of retroviruses: human T-lymphotropic virus types I and II compared with human immunodeficiency virus type 1. Transfusion. 1994;34 (6):478-483. doi:10.1046/j.1537-2995.1994.34694295061.x

55. Zou S, Dorsey KA, Notari EP, et al. Prevalence, incidence, and residual risk of human immunodeficiency virus and hepatitis $\mathrm{C}$ virus infections among United States blood donors since the introduction of nucleic acid testing. Transfusion. 2010;50 (7):1495-1504. doi:10.1111/j.1537-2995.2010.02622.x

56. Newman L, Rowley J, Hoorn SV, et al. Global estimates of the prevalence and incidence of four curable sexually transmitted infections in 2012 based on systematic review and global reporting. PLoS One. 2015;10(12):e0143304. doi:10.1371/journal.pone.0143304

57. Tagny CT. Syphilis and blood safety in developing countries. In: Sato NS, editor. Syphilis - Recognition, Description and Diagnosis. InTech; 2011. Available from: http://www.intechopen.com/books/ syphilis-recognition-description-and-diagnosis/syphilis-and-bloodsafety-indeveloping-countries. Accessed August 16, 2020.
58. Orton S. Syphilis and blood donors: what we know, what we do not know, and what we need to know. Transfus Med Rev. 2001;15 (4):282-291. doi:10.1053/tm.2001.26956

59. Kaur G, Kaur P. Syphilis testing in blood donors: an update. Blood Transfus. 2015;13(2):197-204.

60. Montoya PJ, Lukehart SA, Brentlinger PE, et al. Comparison of the diagnostic accuracy of a rapid immunochromatographic test and the rapid plasma reagin test for antenatal syphilis screening in Mozambique. Bull World Health Organ. 2006;84(2):97-104. doi:10.2471/BLT.04.018663

61. Malaria strategic plan, Pakistan - 2015-20. Directorate of Malaria Control. Available from: http://dmc.gov.pk/index.php?option=com_con tent\&view=article\&id=84\&Itemid=84. Accessed August 16, 2020.

62. Mungai M, Tegtmeier G, Chamberland M, Parise M. Transfusiontransmitted malaria in the United States from 1963 through 1999. $N$ Engl J Med. 2001;344(26):1973-1978. doi:10.1056/NEJM200106 283442603

63. Zoon K. Recommendations for Deferral of Donors for Malaria Risk: Letter to All Registered Blood Establishments. Rockville, Maryland: US Department of Health and Human Services. Food and drug administration; 1994.

64. Moiz B. Prevention of transfusion transmitted malaria in an endemic area - a challenge for blood banks. Infect Dis J Pak. 2004;13 (4):96-98.

65. Choudhury N, Jolly J, Mahajan R, Ganguly N, Dubey M, Agnihotri S. Malaria screening to prevent transmission by transfusion: an evaluation of techniques. Med Lab Sci. 1991;48(3):206-211.

66. Blood safety and availability. World Health Organization. Available from: https://www.who.int/en/news-room/fact-sheets/detail/bloodsafety-and-availability. Accessed August 16, 2020.

67. Towards $100 \%$ voluntary blood donation, a global framework for action. World Health Organization. Available from: https://www.who.int/blood safety/publications/9789241599696/en/. Accessed August 16, 2020.

68. Sibinga CTS, Oladejo MA, Adejumo OH, et al. A global survey of clinicians' awareness, accessibility, utilization of e-continuous education, and quality of clinical blood use: policy considerations. Int J Clin Transfus Med. 2017;5:69. doi:10.2147/IJCTM.S136047

69. Global collaboration for blood safety 2004. World Health Organization. Available from: https://www.who.int/bloodsafety/ GCBS Report NOV 2004.pdf?ua=1. Accessed August 16, 2020.

70. Faber JC. Haemovigilance procedure in transfusion medicine. Hematol J. 2004;5(Suppl 3):S74-S82. doi:10.1038/sj.thj.6200427

71. Naz S, Umair MM, Hameed A. Evolution of blood banks of Islamabad in ten years (2006-2016). Ann PIMS. 2018;14(2):127-134.

72. Luby S, Khanani R, Zia M, et al. Evaluation of blood bank practices in Karachi, Pakistan, and the government's response. J Pak Med Assoc. 2006;56(1 Suppl 1):S25-S30.

73. Blood safety in Pakistan 2018. World Health Organization. Available from: http://www.emro.who.int/pak/programmes/blood-safety.html. Accessed August 16, 2020. 


\section{Publish your work in this journal}

The Journal of Blood Medicine is an international, peer-reviewed, open access, online journal publishing laboratory, experimental and clinical aspects of all aspect pertaining to blood based medicine including but not limited to: Transfusion Medicine; Blood collection, Donor issues, Transmittable diseases, and Blood banking logistics; Immunohematology; Artificial and alternative blood based therapeutics; Hematology; Biotechnology/nanotechnology of blood related medicine; Legal aspects of blood medicine; Historical perspectives. The manuscript management system is completely online and includes a very quick and fair peer-review system. Visit http://www.dovepress.com/testimonials.php to read real quotes from published authors. 